\title{
Formação e Atuação Profissional de Médicos Egressos de uma Instituição Privada do Pará: Perfil e Conformidade com as Diretrizes Curriculares Nacionais
}

\section{Training and Professional Activities of Medical Graduates from a Private Institution of Pará: Profile and Compliance with the National Curricular Guidelines}

Cristiane Ribeiro Maués Bruno Acatauassu Paes Barreto Márcia Bitar Portella

Haroldo José de Matos, ${ }^{I, I I}$ Julio Cristovão Carvalho dos Santos ${ }^{I I I}$

RESUMO

\section{PALAVRAS-CHAVE}

- Médicos Egressos.

- Ensino Superior.

- Mercado de Trabalho.

\section{KEY-WORDS}

- Former Students.

- Medical Training.

- Labor Market.

Recebido em: 30/1/2018 Aceito em: 4/4/2018

\begin{abstract}
O estudo objetivou conhecer o perfil sociodemográfico, de formação e atuação profissional de médicos egressos de uma instituição privada, observar a conformidade deste perfil com o preconizado pelas Diretrizes Curriculares Nacionais (DCN) e contribuir para o Programa de Acompanhamento de Egressos. O instrumento de coleta de dados foi um questionário validado, adaptado e enviado online aos egressos das primeiras quatro turmas. A maioria era composta por mulheres, jovens, solteiras, com renda mensal de até dez salários mínimos. O curso contribuiu totalmente ou em grande parte para a formação na atenção básica e uma formação humanista, generalista, crítico-reflexiva e ética. Os egressos são atuantes no SUS, como generalistas, alocados na Região Norte, sentindo-se razoavelmente preparados para o mercado de trabalho e competentes. Houve tendência de conformidade deste perfil com o preconizado pelas DCN, e a contribuição para o Programa de Acompanhamento de Egressos se deu por meio da elaboração da Revista do Egresso.
\end{abstract}

ABSTRACT
The objectives of this study were to know the socio-demographic profile, training and professional
performance of physicians graduates of a private institution, to observe the compliance of this profile
with the one advocated by the DCN and to contribute to the Program of Accompaniment of Gra-
duates. The instrument of data collection was a questionnaire validated, adapted and sent online to
the graduates of the first four classes. Most were women, young, single, with monthly income up
to 10 minimum wages. The course contributed wholly or largely to training in basic Attention and
humanistic training, generalist, critical-reflexive and ethical. The graduates are active in the SUS, as
generalists, allocated in the North region, feeling reasonably prepared for the job market and compe-
tent. There was a tendency of compliance of this profile with the one recommended by the DCN and
the contribution to the Program of Accompaniment of Graduates was given through the elaboration
of Revista do Egresso.

I Universidade do Estado do Pará, Belém, Pará, Brasil. 


\section{INTRODUÇÃO}

Nas últimas décadas, inúmeras foram as modificações ocorridas no processo de ensino-aprendizagem nos cursos da área da saúde. A motivação destas mudanças foi a necessidade de uma formação acadêmica mais eficaz e que resultasse em um egresso com compreensão ampliada de saúde e visão social ${ }^{1}$.

Na Medicina, devido ao grande volume de conhecimento necessário à prática médica, o futuro profissional precisa ter a capacidade de aprender a aprender desde a graduação. Com isso, os currículos tradicionais vêm sendo reestruturados com cenários de prática que favorecem a interação entre profissionais de saúde, usuários, estudantes e professores².

A prioridade dos educadores em saúde deve ser reconhecer, estimular e investigar os fatores que despertam no aluno um interesse mais abrangente pelo campo do saber médico, traduzido numa formação mais sólida e não restrita e incompleta, e numa prática profissional favorável à atenção básica ${ }^{3,4}$.

O grande desafio das instituições de ensino superior (IES) é formar, no caso da Medicina, médicos mais humanistas e capazes de atuar com qualidade na atenção à saúde das pessoas, respeitando a integralidade, e em equipe multiprofissional, características indispensáveis ao profissional inserido no Sistema Único de Saúde (SUS). Conhecer saúde coletiva e participar da construção de políticas públicas e da organização de serviços de saúde tornaram-se competências imprescindíveis à atuação do futuro médico ${ }^{5,2,6}$.

Saber diagnosticar e tratar são competências específicas, sem as quais o egresso não exerce a medicina, porém o conhecimento técnico isolado é insuficiente para o manejo de casos complexos reais. Devem fazer parte do cotidiano do ensino e aprendizagem algumas competências amplas, como integralidade, acessibilidade ao paciente, responsabilidade, compromisso, considerar as necessidades da população e o cuidar de $\mathrm{si}^{1}$

Além disso, a abordagem interdisciplinar torna-se fundamental para atender às necessidades de saúde do indivíduo e da comunidade devido à transição epidemiológica resultante do envelhecimento populacional. Ela se caracteriza pelo predomínio de doenças crônico-degenerativas, o que demanda redirecionamento das estratégias na saúde, com impacto na formação de profissionais de saúde ${ }^{2}$.

E, ainda, sendo o acesso à saúde um direito social, a população também apresenta novas exigências, com sérias implicações na relação médico-paciente. $\mathrm{O}$ início da atividade profissional para o médico recém-formado está inserido, portanto, num contexto de grande expectativa pessoal e da sociedade, devido à cobrança por atenção integral à saúde e relações mais humanizadas 5
Por outro lado, a atuação profissional do egresso também assume papel importante na certificação e acreditação das escolas médicas. Políticas institucionais devem ser fundamentadas em estudos sobre os egressos, pois, ao obterem feedback dos seus ex-alunos, as IES aplicam mudanças necessárias em seus currículos, reduzindo as lacunas existentes entre a formação acadêmica e as reais necessidades do mercado de trabalho ${ }^{7}$

Sendo assim, o presente estudo foi motivado pela necessidade de conhecer a atuação profissional de médicos formados por uma instituição com estrutura curricular inovadora e da qual se espera total consonância com as Diretrizes Curriculares Nacionais, uma vez que seu modelo pedagógico foi desenhado com este fim.

Após finalizado, este estudo poderá contribuir para a melhoria do ensino médico no Estado do Pará e da qualidade da assistência prestada à população desta região, pois os resultados serão úteis para uma discussão sobre as DCN e o perfil de médico esperado.

\section{REFERENCIAL TEÓRICO}

Escolas médicas no Brasil (2000-2016)

Desde o início do século XXI, o número de escolas médicas no Brasil vem crescendo de maneira significativa, o que coloca o País no segundo lugar do mundo em número de faculdades de Medicina, atrás da Índia e à frente dos Estados Unidos ${ }^{8}$.

Entre 2000 e 2015, surgiram 142 novas escolas médicas, das quais $64 \%$ são privadas. Atualmente, existem 272 escolas, na maioria privadas, com maior concentração nas regiões $\mathrm{Su}$ deste e Sul e menor nas regiões Norte e Nordeste, ofertando mais de 23 mil vagas de ingresso ao curso médico ${ }^{8,9}$.

A abertura de novos cursos de Medicina faz parte de um conjunto de medidas governamentais que busca atender à carência de profissionais em várias regiões do País. Entre estas medidas estão: o Programa de Valorização do Profissional da Atenção Básica (Provab), revalidação de diplomas médicos expedidos por instituições de educação superior estrangeiras (Revalida) e o Programa Mais Médicos, que prevê a criação de mais de 10 mil vagas em cursos de Medicina ${ }^{10,11}$.

Além disso, o Ministério da Educação anunciou que os alunos que ingressarem no curso de Medicina a partir de 2015, após completarem os seis anos de formação, passarão um ano no serviço de Atenção Básica do SUS e mais um ano nos serviços de Urgência e Emergência, como o Samu. O discurso é que esta medida permite uma formação mais generalista, um afluxo maior de profissionais ao SUS e maior oferta de médicos ao País.

Por outro lado, uma ampla e recente pesquisa sobre a demografia médica no Brasil mostra que o total de médicos cres- 
ce seis vezes mais do que a população. Porém, a distribuição por regiões e estados mostra maior concentração de médicos no Sudeste, Sul e Centro-Oeste. A Região Norte concentra o menor número desses profissionais, e o Pará tem índices comparáveis aos de países africanos, com menos de um médico por mil habitantes ${ }^{8,10}$.

E, ainda, os profissionais concentram sua atuação nos grandes centros, deixando as periferias carentes de atenção à saúde. Mesmo o Programa de Saúde da Família (PSF), também criado pelo governo federal, promove oferta de emprego médico, mas não resolve a situação do profissional nas cidades do interior. As principais causas são falta de condições de trabalho e má remuneração ${ }^{11}$.

Neste cenário, criou-se uma discussão sobre a qualidade do ensino prestado aos futuros médicos. Baixa qualificação de professores, baixa produção de conhecimento, descontextualização da prática, desumanização, incorporação indiscriminada de tecnologias e currículos arcaicos são alguns dos problemas das escolas médicas brasileiras ${ }^{2}$.

Em 2015, um levantamento do Conselho Federal de Medicina $(\mathrm{CFM})^{12}$ revelou que metade dos municípios com escolas médicas não possui estrutura para formar adequadamente os profissionais, o que é traduzido pela insuficiência de leitos públicos, de equipes de atenção básica e de hospitais de ensino em cidades que possuem cursos de Medicina.

Segundo esse levantamento, 60\% dos municípios que receberam novas escolas entre 2013 e julho de 2015 não atendem à exigência de no mínimo cinco leitos por aluno, e 18 destes não respeitam a proporção ideal de até três alunos por Equipe de Saúde da Família (ESF). Das 158 cidades com escolas médicas no País, 74 não dispõem de leitos em quantidade necessária por aluno, 68 não atendem à proporção ideal de alunos por ESF, e 89 não possuem nenhum hospital de ensino habilitado.

Contudo, dados do Conselho Federal de Medicina mostram que cerca de 23 mil egressos chegam anualmente ao mercado de trabalho em condições desafiadoras e situações-limite, para as quais nem sempre foram preparados durante a formação. Esta chegada se dá num contexto de grande expectativa pessoal e da sociedade por uma educação médica capaz de formar recursos humanos adequados às reais demandas da população.

\section{Diretrizes Curriculares Nacionais}

Ao lado da abertura indiscriminada de escolas médicas, as discussões sobre a formação dos profissionais de saúde, notadamente dos médicos, têm sido frequentes nos últimos anos. O despreparo de recém-formados para atuarem na complexidade do SUS e compreenderem sua gestão e a ação do controle da sociedade sobre o setor é observado frequentemente, e esse é um dos nós que é preciso desatar na formação ${ }^{6}$.

O questionamento do processo de ensino do currículo tradicional, baseado no modelo flexneriano, biomédico e curativo, impulsionou a uma mudança paradigmática para outro modelo, orientado pelo binômio saúde-doença em seus diferentes níveis de atenção, na perspectiva da integralidade da assistência $^{2,13}$

Esta mudança é marcada pela substituição de currículos rígidos, compostos por disciplinas cada vez mais fragmentadas, com priorização de atividades teóricas, por currículos flexíveis, modulares, dirigidos para a aquisição de competências profissionais $^{13}$.

Neste contexto, a Câmara de Educação Superior do Conselho Nacional de Educação propôs estratégias para modificar o cenário da educação brasileira. Elaboradas em meados da década de 1990, as Diretrizes Curriculares Nacionais para os cursos da área da saúde foram homologadas em 2001 e 2002 como resultado da correlação de forças entre diferentes ideo$\operatorname{logias}^{14,6}$.

Em 2014, houve uma reformulação das DCN, o que trouxe mudanças estruturantes em alguns aspectos da formação médica, como, por exemplo, redefinição de carga horária na atenção básica e nos serviços de urgência e emergência do SUS, considerando o período de dois anos como tempo mínimo de internato ${ }^{15}$.

As Diretrizes propõem uma estrutura curricular desenvolvida por metodologias que privilegiem a participação ativa do aluno na construção do conhecimento e na integração entre os conteúdos, assegurando a indissociabilidade do ensino, pesquisa e extensão ${ }^{14}$. A principal função do educador é criar situações e condições de aprendizagem nas quais a construção de saberes se dá tendo por base conhecimentos prévios frente a situações-problema reais ou simuladas ${ }^{14}$.

No entanto, a aprovação das DCN não é suficiente para que seus eixos norteadores sejam incorporados ao ensino, uma vez que isto se dá na prática da implantação de cada currículo em cada escola e na forma como será avaliado o resultado dessas mudanças ${ }^{6}$.

No Brasil, várias escolas médicas vêm sendo desafiadas a adotar metodologias ativas de ensino que incluam em seus ambientes de aprendizagem práticas pedagógicas inovadoras e integradoras, como a Aprendizagem Baseada em Problemas, termo originado do inglês Problem Based Learning ( $P B L$ ), problematização, práticas de campo e estudos temáticos ${ }^{16,17,1}$

Na prática, na maioria das IES do País, ainda predomina a formação de um profissional biologicista, especialista, com poucas habilidades para lidar com a complexidade do ser hu- 
mano e com poucos conhecimentos do sistema público de saúde e das reais necessidades da população ${ }^{16}$.

No Pará, algumas instituições aderiram a este movimento de mudança curricular e têm disponibilizado aos estudantes de Medicina múltiplos cenários de prática em diferentes níveis de atenção, como adequação às DCN. Entre elas, o Centro Universitário do Estado do Pará (Cesupa), instituição privada, cujo curso médico foi implantado em 2007, já contribuiu com a formação de 413 profissionais médicos até dezembro de 2016, e seu modelo pedagógico segue as recomendações das Diretrizes Curriculares Nacionais do Curso de Graduação em Medicina - Conselho Nacional de Educação (MEC).

O curso de Medicina do Cesupa propicia ao estudante o internato de dois anos, inserção precoce do aluno na prática, (des) hospitalização e oferta de múltiplos cenários de prática, com ênfase na atenção primária. E, ainda, o internato comunitário, em cidades do interior, favorecendo o contato com uma realidade desconhecida pelo aluno e distante dos grandes centros.

\section{O perfil do egresso de Medicina}

Em relação ao perfil do egresso do curso de Medicina, as Diretrizes propõem que:

o médico deve ter formação generalista, humanista, crítica, reflexiva e ética; ser capacitado a atuar em diferentes níveis de atenção, com senso de responsabilidade social e compromisso com a cidadania, como promotor da saúde integral do ser humano. ${ }^{14,15}$

Para isto, o aprendizado se dá por competências gerais, que são: atenção à saúde, tomada de decisões, comunicação, liderança, administração e gerenciamento, e educação permanente. Além disso, a formação acadêmica visa a um egresso com compreensão ampliada de saúde e uma visão social pertinente, cujo perfil está atrelado ao cuidado integral e conhecimento da realidade em que atua ${ }^{14,1}$.

Na literatura estão disponíveis alguns trabalhos sobre o perfil de egressos de cursos de Medicina com abordagem mais sociodemográfica que curricular, inclusive no Estado do Pará. Nota-se que o perfil do egresso tem sofrido poucas mudanças ao longo das décadas.

Na Região Norte, um amplo estudo sobre os egressos de Medicina do Pará revelou que até a primeira metade do século XX (1901-1950) o modelo era liberal e de formação generalista, com predomínio de jovens, do sexo masculino, com atuação profissional em clínica geral e setor público ${ }^{18}$.

A partir da segunda metade (1951-2000), houve transição para o modelo científico e tecnicista, mantendo-se o predomí- nio de jovens do sexo masculino, porém com aumento da presença feminina na graduação. A maioria passou a atuar como especialista, tanto no setor público quanto no privado, com quase totalidade de busca por pós-graduação ${ }^{18}$.

A partir dos anos 2000, outros estudos em outras regiões do País demonstraram pouca mudança no perfil do egresso médico, exceto a crescente participação feminina ${ }^{11,19-23}$.

Por outro lado, o movimento questionador do ensino médico no País e a homologação das DCN também impactaram os objetivos de pesquisas até então realizadas com egressos. Nos últimos anos, novos estudos foram desenhados a fim de conhecer o perfil sociodemográfico dos egressos e também relacionar este perfil com o aparelho formador.

Neste aspecto, vale citar os estudos de Sakai e Cordoni ${ }^{19}$, Castellanos et al. ${ }^{21}$, Novaes et al. ${ }^{24}$ e Oliveira e Alves ${ }^{5}$, que abordam o perfil do egresso médico sob a temática do novo currículo proposto pelas DCN.

Durante a formação, o cenário restrito e a falta de integração com os serviços de saúde e seus profissionais levam a um comprometimento da qualidade dos formandos, e a prática médica ainda é baseada no modelo flexneriano mas se encontra em transição ${ }^{19}$.

Mesmo sendo uma referência bastante difundida na discussão sobre mudanças na educação médica no Brasil, a maioria dos formandos não conhece as DCN, e a abordagem multidisciplinar é uma concepção adotada por uma minoria dos cursos, o que evidencia uma distância entre a ênfase dada pela maioria das escolas médicas e o perfil do médico que a comunidade necessita ${ }^{5}$.

Futuros egressos precisam de mais discussões sistemáticas sobre aspectos éticos e bioéticos integradas com as atividades práticas para estimular e fortalecer a reflexão e o treinamento de habilidades adequadas ${ }^{24}$. Tem havido por parte dos egressos maior valorização da atenção primária em saúde, reconhecendo sua posição estratégica nesse campo ${ }^{21}$.

Contudo, a literatura ainda carece de mais dados referentes aos egressos de cursos com currículo inovador, baseado em metodologias ativas de ensino, dos quais se espera total consonância com o perfil do egresso exposto nas Diretrizes.

\section{Programa de acompanhamento de egressos}

Por nortear o caminho da formação profissional, a exposição do perfil do egresso tornou-se uma exigência do Ministério da Educação e representa um instrumento de avaliação externa de instituições de educação do Sistema Nacional de Avaliação da Educação Superior (Sinaes). Nesta avaliação, a dimensão é a Política de Atendimento aos Estudantes; o grupo de indicador é o Egresso; e os indicadores são Política de Acom- 
panhamento do egresso e Programas de educação continuada voltados para o egresso ${ }^{25}$.

Faz parte do indicador de maior pontuação a criação de uma base de dados com informações atualizadas dos egressos, sendo atribuída nota máxima quando existe intenso relacionamento com o egresso por meio de política de acompanhamento ou programas de educação continuada ${ }^{25}$.

Ainda como parte da promoção de um relacionamento contínuo entre IES e seus egressos, o vínculo institucional tem a finalidade de integrar o egresso junto à IES, considerando-se possibilidades de: congregação de ex-alunos, reatar laços de amizade do passado, grupo de relacionamento de profissionais, participação em eventos técnicos e científicos, e egresso como palestrante para novos alunos ${ }^{7}$.

Sendo assim, os ex-alunos representam o elo entre a formação e a prática médica. Ao avaliarem o currículo que tiveram e a profissão que exercem, eles se tornam agentes ativos no processo de mudanças de suas escolas, bem como na determinação das necessidades referentes à educação permanente ${ }^{19}$.

O acompanhamento e o registro dos egressos mostram-se, portanto, fundamentais para que as instituições de ensino superior, sejam públicas ou privadas, obtenham o feedback necessário à avaliação do ensino oferecido, realizem mudanças em seus currículos e processos de ensino-aprendizagem e sintonizem a estrutura curricular com as necessidades de formação para o mercado ${ }^{7}$.

No Cesupa, existe o Programa de Acompanhamento de Egressos por meio da Associação dos Antigos Alunos e do Portal do Egresso, onde o ex-aluno, após realizar cadastro online, pode consultar e emitir histórico escolar, atualizar informações pessoais e profissionais, e emitir carteira de egresso, com a qual tem acesso a descontos em cursos de pós-graduação da própria IES ou em universidades internacionais e cursos de idiomas.

\section{OBJETIVOS}

\section{Geral}

- Conhecer o perfil de formação e atuação profissionais de egressos de um curso de Medicina baseado em metodologias ativas de ensino.

\section{Específicos}

- Descrever o perfil sociodemográfico, de formação e atuação profissional dos egressos;

- Observar a existência ou não de conformidade do perfil desses egressos com o perfil do egresso preconizado pelas Diretrizes Curriculares Nacionais;

- Contribuir com o Programa de Acompanhamento de Egressos da IES por meio da elaboração da Revista do Egresso.

\section{METODOLOGIA}

Tipo de estudo

O presente estudo apresenta caráter quantitativo, transversal e exploratório descritivo.

\section{Local da pesquisa}

A pesquisa ocorreu no Centro Universitário do Estado do Pará (Cesupa), no curso de Medicina, da cidade de Belém, Estado do Pará

\section{População, amostra e coleta de dados}

O estudo teve como público-alvo os egressos do curso de Medicina do Cesupa formados entre dezembro de 2012 e junho de 2014, o que correspondeu a 171 profissionais oriundos das primeiras quatro turmas formadas.

Para o cálculo amostral, considerou-se nível de significância de $5 \%$, poder de $90 \%$ e chance de $50 \%$ de cada ex-aluno participar ou não do estudo. A amostra estimada foi de 119 médicos, segundo o cálculo de amostragem a seguir:

$$
\begin{aligned}
& \mathrm{n}_{0}=1 / \mathrm{E}^{2} \\
& \mathrm{n}=\mathrm{N} \times \mathrm{n}_{0} / \mathrm{N}+\mathrm{n}_{0}
\end{aligned}
$$

onde:

$\mathrm{n}_{0}$ é a primeira aproximação do tamanho da amostra;

$E^{2}$ é a margem de erro (ex.: $5 \%=0,05$ )

N é o número de elementos da população;

n é o tamanho da amostra.

Para a presente pesquisa foi adotada a definição de egresso como sendo o ex-aluno diplomado pelo curso de Medicina da IES7.

O instrumento de coleta dos dados foi um questionário (Apêndice A) enviado online aos ex- alunos da IES. Os meios de contato dos egressos (telefones e $e$-mails) foram fornecidos pelo Cesupa, por meio da Secretaria do curso.

Esse questionário foi elaborado e validado por Filisbino e Moraes $^{4}$ e adaptado à presente pesquisa para contemplar egressos, uma vez que na sua elaboração e validação foi aplicado em discentes do internato. A adaptação do questionário foi baseada nas DCN de 2001, uma vez que os egressos do presente estudo fazem parte de turmas concluintes prévias à implantação das novas DCN.

O questionário foi composto por três partes. A primeira consta de perguntas que abordam o perfil sociodemográfico, a segunda contém perguntas sobre o perfil de formação, e a terceira, sobre a prática profissional dos egressos. Para acesso ao questionário, um link permitia a resposta a ele somente após o acordo com o Termo de Consentimento Livre e Esclarecido (Apêndice B). 
O prazo para devolução do questionário foi de até 120 dias contados a partir da data de envio. A própria pesquisadora realizou busca ativa dos egressos que atrasaram a devolução do questionário, por meio de e-mails, redes de relacionamentos digitais ou telefonemas. Para ampliar a localização de egressos, a pesquisadora criou uma página para a pesquisa numa rede social e empenhou-se para encontrar os ex-alunos.

Os critérios de inclusão foram: ser egresso do curso de Medicina do Cesupa, com formatura de dezembro de 2012 a junho de 2014, estar de acordo em participar da pesquisa, sendo este acordo expresso mediante a marcação online no campo "de acordo" do TCLE, e responder ao questionário enviado para pesquisa.

\section{Análise estatística dos dados}

Os dados obtidos foram consolidados sob a forma de variáveis quantitativas e qualitativas. As variáveis qualitativas foram apresentadas sob a forma de distribuição de frequências. As variáveis quantitativas foram apresentadas por medidas de tendência central e de variação. Tabelas e gráficos foram elaborados utilizando-se os programas Microsoft Excel e Microsoft Word versões 2013.

A avaliação da adequação da formação médica às Diretrizes Curriculares foi realizada por meio da construção de dois Indicadores numéricos: o Perfil de Formação Profissional (PFP) e o Perfil de Prática Profissional (PPP). Esses indicadores foram apresentados na forma de uma variável quantitativa contínua, que variou de zero (pior adequação) e foi crescente até atingir o valor máximo, cem (melhor adequação).

A avaliação das relações desses indicadores em relação às variáveis qualitativas foi realizada preferencialmente pelo teste t de Student e pela Análise de Variância (Anova); quando não houve condições de normalidade, foram aplicados métodos não paramétricos. A avaliação da correspondência desses indicadores em relação a variáveis quantitativas foi realizada pelo método de Pearson ${ }^{25}$.

Ficou previamente fixado o nível alfa = 0,05 (erro alfa 5\%) para rejeição da hipótese nula. A análise estatística foi realizada por meio dos programas de análises estatísticas BioEstat versão 5.3 e SAS Statistical Package.

Fórmula de cálculo dos indicadores de adequação curricular:

$$
\begin{aligned}
& \mathrm{PFP}=\text { média }(\text { questões } 2 \text { a } 8)^{*} 100 / 5 \\
& \mathrm{PPP}=\text { média }(\text { questões } 4 \text { a } 7)^{*} 100 / 5
\end{aligned}
$$

\section{Produto técnico da pesquisa}

Como produto desta pesquisa, foi elaborada uma revista que fornece informações à comunidade acadêmica sobre os egressos do curso como uma importante estratégia de integração e troca de informações entre o ex-aluno e o órgão formador. A revista pretende contribuir com o Programa de Acompanhamento de Egressos da IES como uma possibilidade de vínculo institucional para se aproximar dos ex-alunos.

Para elaborar o conteúdo da revista, os egressos foram convidados a participar ativamente por meio de sugestões de temas, envio de fotos e arquivos de acervo pessoal e relatos de experiência. A coordenação e a redação ficaram sob responsabilidade da autora, e para o projeto gráfico e diagramação foi convidado um profissional especialista da área.

\section{Avaliação de riscos e benefícios}

Os riscos da pesquisa são mínimos e relacionados à exposição de informações. Para minimizá-los, os aspectos éticos foram plenamente respeitados durante o desenvolvimento da pesquisa, garantindo o total anonimato dos participantes. As informações obtidas foram confidenciais e usadas exclusivamente para fins de pesquisa, sendo tomadas todas as precauções para preservá-las, sendo que os dados coletados não foram analisados individualmente, mas em conjunto, sob a forma de números absolutos e/ou relativos (proporções e razão).

Durante a execução do projeto, há o risco de os sujeitos pesquisados se sentirem constrangidos pelo fato de os autores do projeto terem acesso às respostas do questionário e desistirem de colaborar na pesquisa. Para tentar reduzir esse ris$\mathrm{co}$, foi relatado o quão importantes esses sujeitos eram para o nosso projeto de pesquisa, foram oferecidos a eles os resultados obtidos na pesquisa e garantida a confidencialidade das informações.

Os benefícios para os sujeitos da pesquisa são a possibilidade de integração com a IES por meio da troca de informações entre o ex-aluno e o órgão formador. Para o pesquisador, o estudo contribui com sua qualificação profissional e aprimoramento técnico-científico. Para a instituição, além de favorecer a melhoria do ensino ofertado, a pesquisa contribui com o Programa de Acompanhamento de egressos. E, ainda, para a comunidade, o benefício é a busca por um ensino médico de excelência, que forme profissionais capazes de atender às demandas de saúde da população.

\section{Questões éticas da pesquisa}

Todos os indivíduos da presente pesquisa foram estudados segundo os preceitos da declaração de Helsinque e do Código de Nuremberg, respeitando as normas de pesquisa envolven- 
do seres humanos do Conselho Nacional de Saúde (Res. CNS $466 / 12)$. O projeto foi submetido à apreciação do comitê de ética em pesquisa em seres humanos do Centro Universitário do Estado do Pará e aprovado sob o no 927.553.

\section{RESULTADOS}

Da totalidade dos questionários enviados, foram obtidas 51 respostas $(42,85 \%)$, assim distribuídas conforme o ano de conclusão do curso de Medicina: ano 2012 - $2^{\circ}$ semestre: 16 respostas ( $31,82^{\%}$ de 40$)$; ano $2013-1^{\circ}$ e $2^{\circ}$ semestres: 24 respostas ( $29,62 \%$ de 81$)$; ano $2014-1^{\circ}$ semestre: 11 respostas ( $22 \%$ de 50 ).

Em alguns casos, a pesquisadora solicitou e foi adicionada à rede social do egresso, mas não recebeu resposta aos pedidos de contribuição com a pesquisa. Os contatos por e-mail foram os mais eficazes, depois dos contatos via redes sociais. Houve casos de não aceitação do egresso em participar da pesquisa por falta de tempo ou outros motivos não explicados.

Em relação a gênero, idade e estado civil, os egressos foram distribuídos em 29 (56,86\%) do sexo feminino e 22 (43,14\%) do masculino, com média de idade de 28,19 anos, sendo $40(78,43 \%)$ solteiros e 11 (21,57\%) casados / união estável, e 18 (35,29\%) com renda mensal entre seis e dez salários mínimos (Tabela 1).

\begin{tabular}{|c|c|c|}
\hline \multicolumn{3}{|c|}{$\begin{array}{c}\text { TABELA } 1 \\
\text { Distribuição dos egressos de Medicina do Cesupa } \\
\text { por gênero, estado civil e renda mensal }\end{array}$} \\
\hline Gênero & Frequência & Porcentagem \\
\hline Feminino & 29 & 56,86 \\
\hline Masculino & 22 & 43,14 \\
\hline Total & 51 & 100,00 \\
\hline \multicolumn{3}{|l|}{ Estado civil } \\
\hline Casado/união estável & 11 & 21,57 \\
\hline Solteiro & 40 & 78,43 \\
\hline Total & 51 & 100,00 \\
\hline \multicolumn{3}{|l|}{$\begin{array}{l}\text { Faixa salarial } \\
\text { (em salários mínimos) }\end{array}$} \\
\hline Até 5 & 12 & 23,53 \\
\hline Entre 6 e 10 & 18 & 35,29 \\
\hline Entre 11 e 15 & 10 & 19,61 \\
\hline Entre 16 e 20 & 4 & 7,84 \\
\hline Acima de 20 & 7 & 13,73 \\
\hline Total & 51 & 100,00 \\
\hline
\end{tabular}

Sobre o perfil de formação profissional, 45 (88,23\%) mostraram-se satisfeitos ou totalmente satisfeitos com o curso de Medicina. A maioria declarou que o curso contribuiu totalmente ou em grande parte para a formação na atenção básica e como médico humanista, generalista, crítico-reflexivo e ético (Gráfico 1).

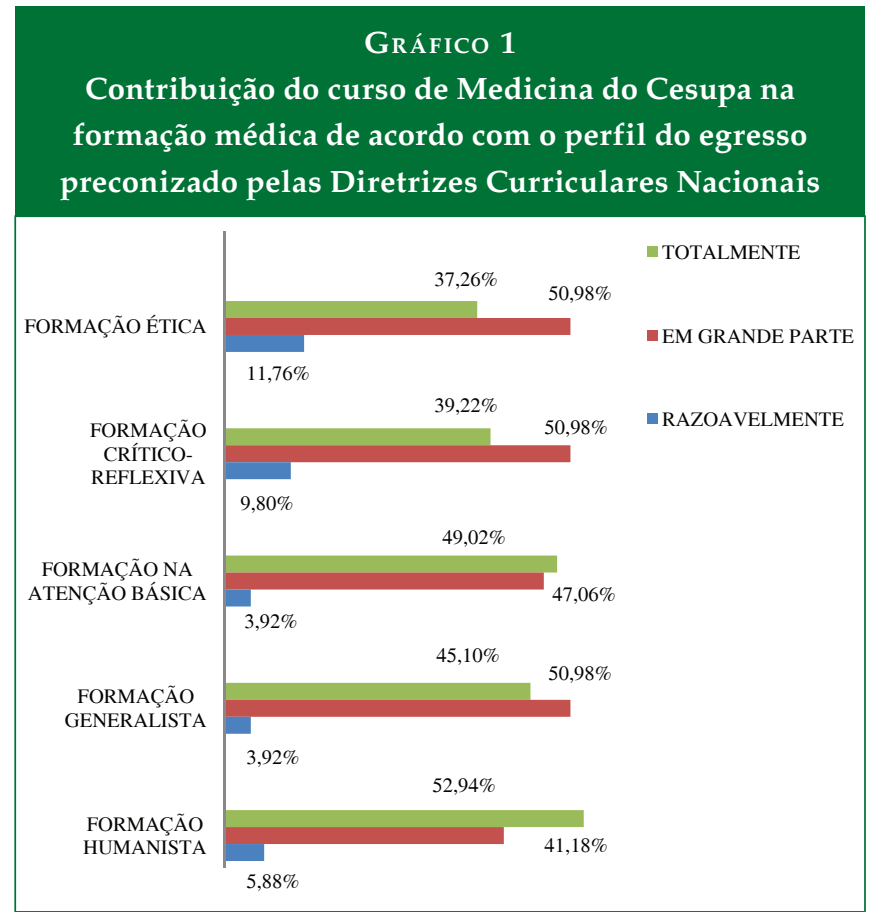

Durante a graduação, 25 (49,04\%) egressos referiram ter tido conhecimento total ou da maior parte do projeto político-pedagógico da IES e apenas 7 (13,72\%) não conheceram o projeto. Em relação ao conhecimento das DCN, apenas 15 $(29,41 \%)$ conheceram a totalidade ou a maior parte de seu conteúdo, enquanto $14(27,45 \%)$ egressos não conheceram (Gráfi$\cos 2$ e 3$)$.

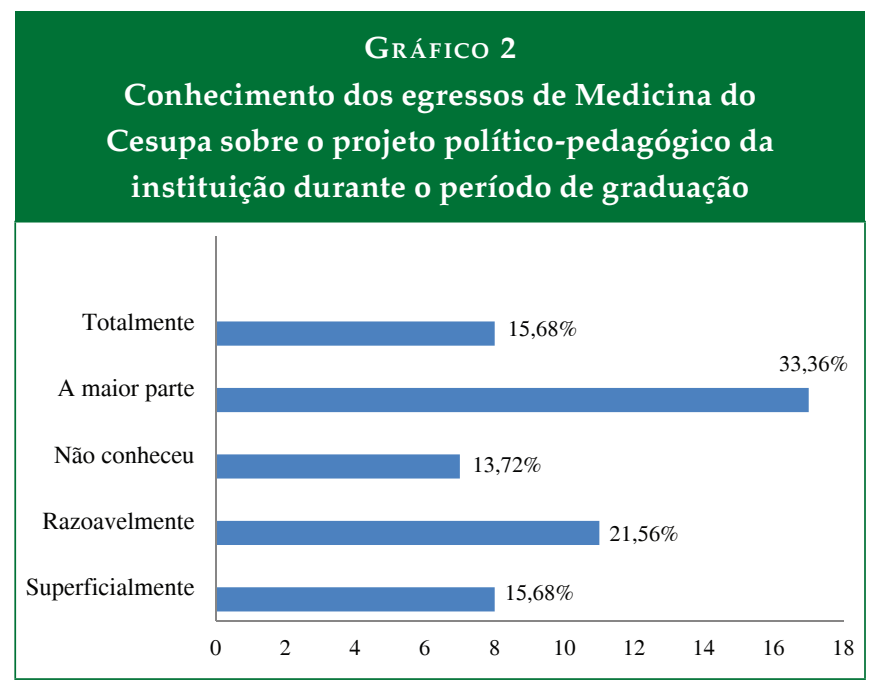




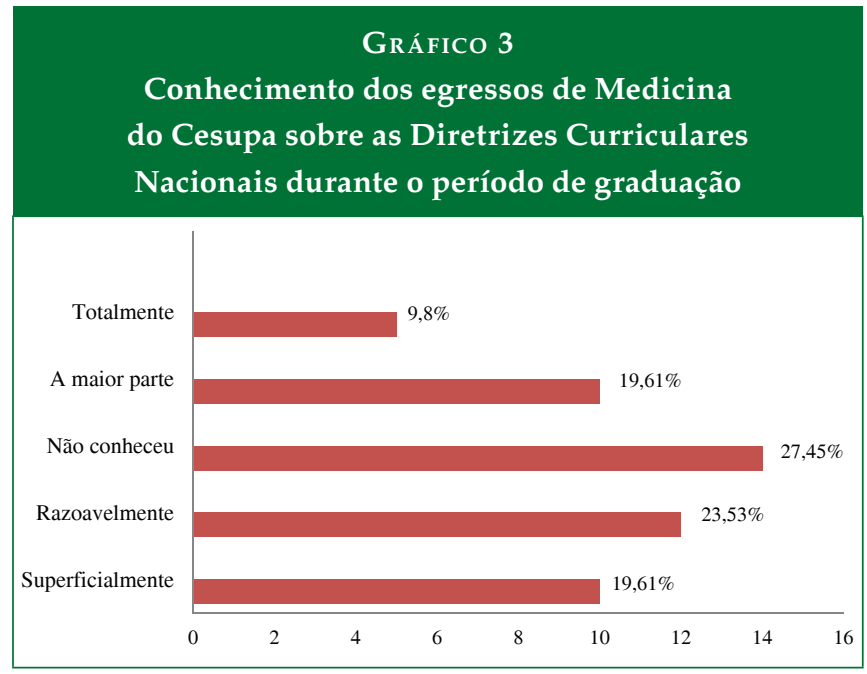

A maioria dos egressos - 36 (70,59\%) - cursa ou cursou residência médica, sendo que as especialidades mais procuradas foram Clínica Médica, Cirurgia Geral e Pediatria (Gráfico 4).

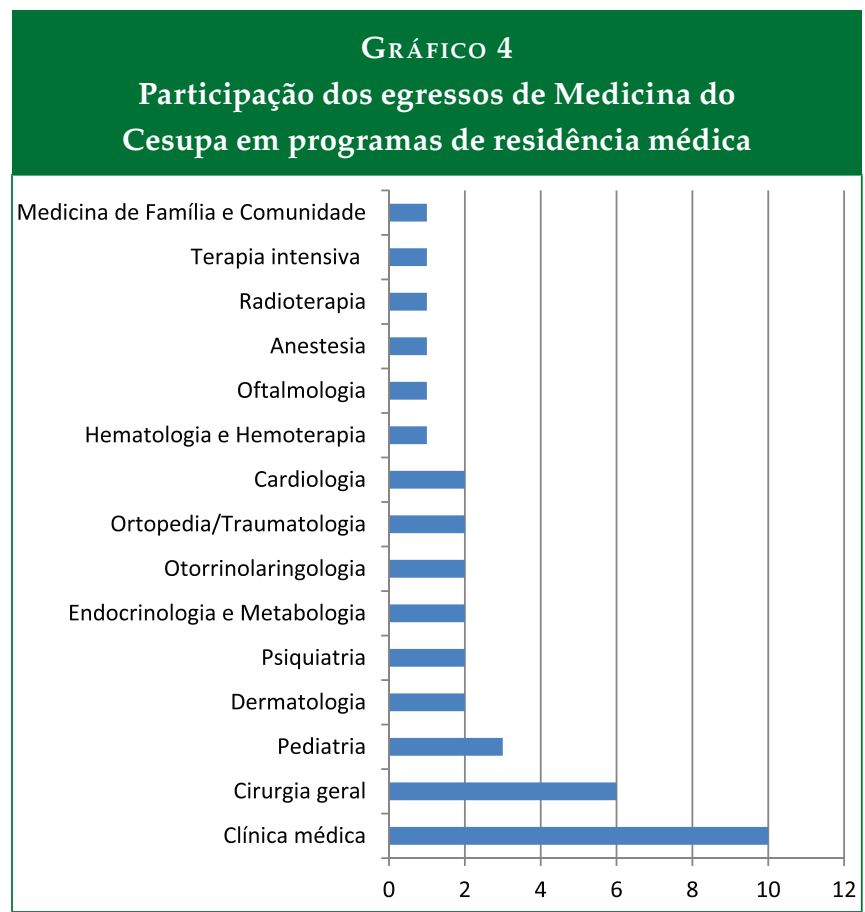

Sobre o perfil de prática profissional, 27 (52,95\%) atuam tanto no SUS como no serviço privado e $41,17 \%$ atuam somente no SUS, totalizando $94,12 \%$ de atuação no sistema público. Trinta e três (66\%) atuam como médicos generalistas, 35 $(68,62 \%)$ alocados na Região Norte, seguida de 9 (17,66\%) no Sudeste, principalmente nas capitais $-44(86,27 \%)$. A maioria - 54,9\% - referiu sensação de estar razoavelmente preparada para o mercado de trabalho (Tabelas 2 e 3, Gráfico 5).

\section{TABELA 2}

Atuação profissional dos egressos de Medicina do Cesupa

Tipo de serviço em que Frequência Porcentagem exerce a profissão

$\begin{array}{lcc}\text { SUS e sistema privado } & 27 & 52,95 \\ \text { Somente serviço público/SUS } & 21 & 41,17 \\ \text { Somente sistema privado } & 3 & 5,88 \\ \text { Total } & 51 & 100,00 \\ \text { Tipo de atuação como médico } & & \\ \text { Médico especialista } & 17 & 33,33 \\ \text { Médico generalista } & 34 & 66,67 \\ \text { Total } & 51 & 100,00\end{array}$

\begin{tabular}{|c|c|c|}
\hline $\begin{array}{l}\text { Distribuição po } \\
\text { profissional dos eg }\end{array}$ & $\begin{array}{l}3 \\
\text { região de a } \\
\text { Medicina c }\end{array}$ & $\begin{array}{l}\text { tuação } \\
\text { o Cesupa }\end{array}$ \\
\hline Estado (capital e interior) & Frequência & Porcentagem \\
\hline Pará (capital) & 29 & 56,87 \\
\hline Pará (interior) & 5 & 9,8 \\
\hline Amapá (capital) & 1 & 1,96 \\
\hline Bahia (interior) & 1 & 1,96 \\
\hline Ceará (capital) & 1 & 1,96 \\
\hline Paraná (capital) & 1 & 1,96 \\
\hline São Paulo (capital) & 7 & 13,72 \\
\hline São Paulo (interior) & 1 & 1,96 \\
\hline Rio de Janeiro (capital) & 1 & 1,96 \\
\hline Distrito Federal (capital) & 4 & 7,84 \\
\hline Total & 51 & 100,00 \\
\hline Região & & \\
\hline Norte & 35 & 68,62 \\
\hline Nordeste & 2 & 3,92 \\
\hline Sul & 1 & 1,96 \\
\hline Sudeste & 9 & 17,66 \\
\hline Centro-Oeste & 4 & 7,84 \\
\hline Total & 51 & 100,00 \\
\hline
\end{tabular}

Os Gráficos 6, 7 e 8 demonstram as competências referidas pelos egressos em relação a atenção à saúde, tomada de decisão, liderança, administração e gerenciamento, e educação permanente. A maioria refere ser competente principalmente na atenção à saúde. 

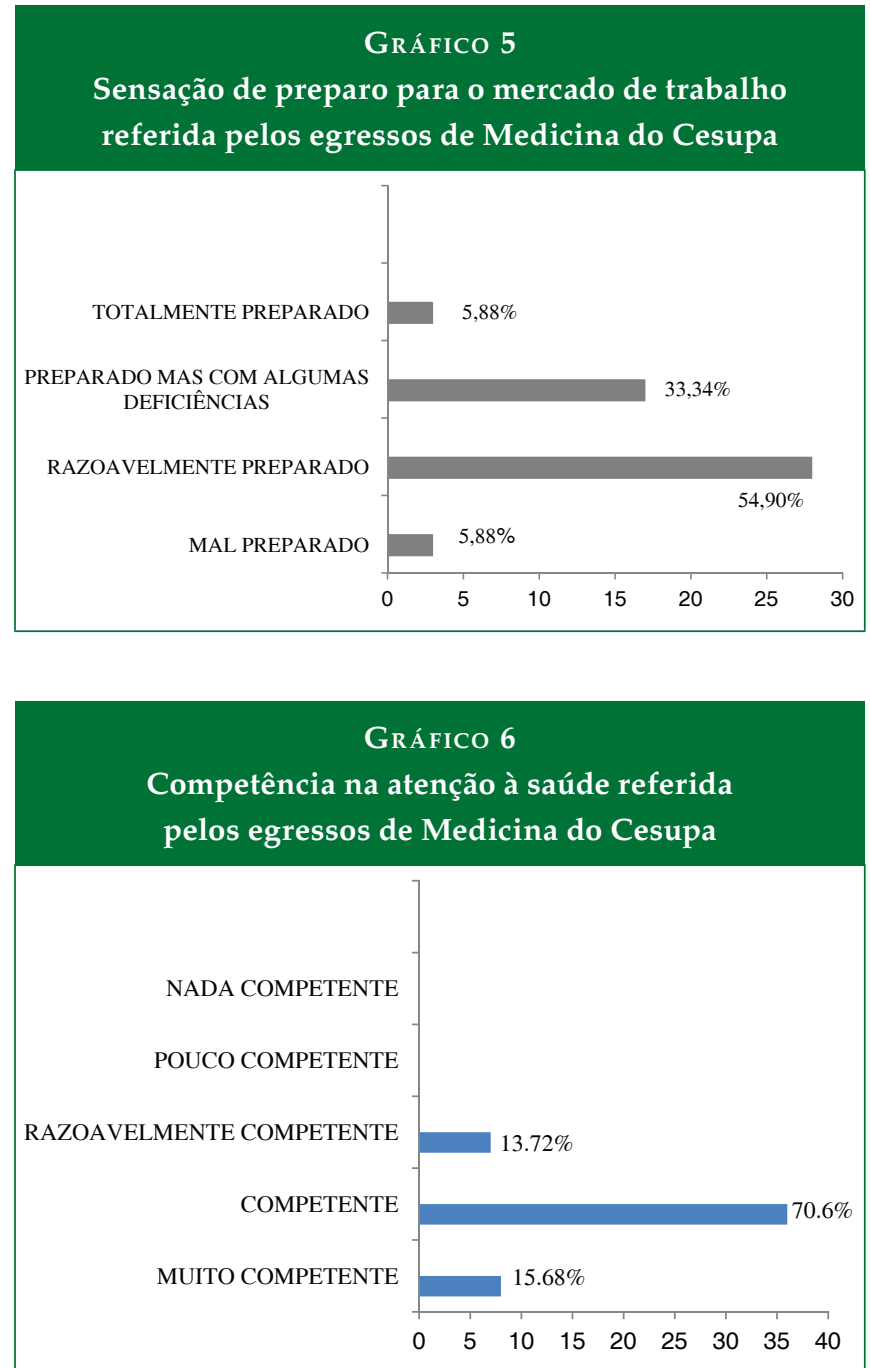

\section{GrÁfico 7}

Competência na tomada de decisão, liderança, administração e gerenciamento referida pelos egressos de Medicina do Cesupa

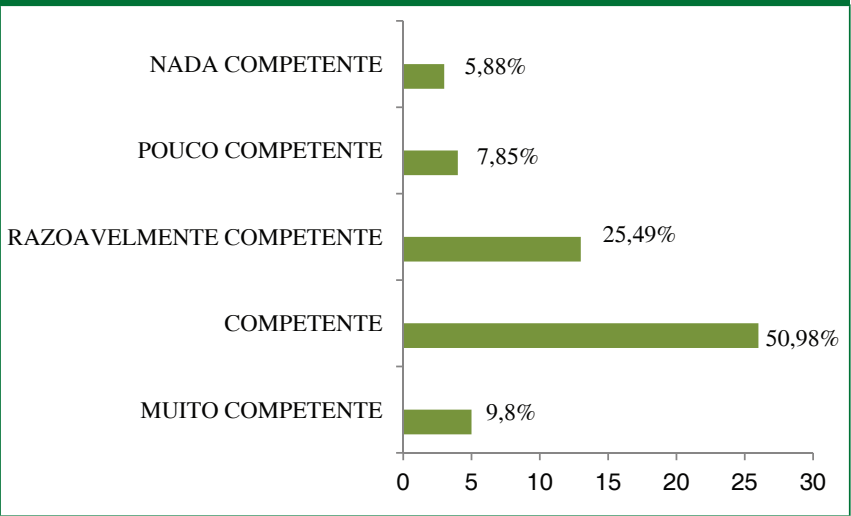

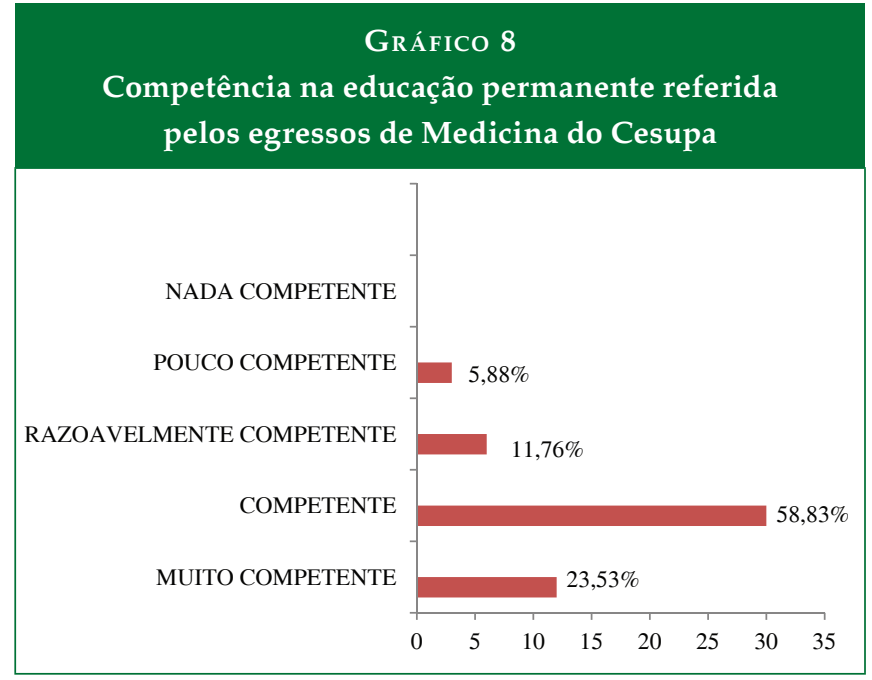

As Tabelas 4 e 5 mostram os valores dos indicadores numéricos Perfil de Formação Profissional (PFP) e Perfil de Prática Profissional (PPP) atribuídos a melhor ou pior adequação às DCN. Em ambos os perfis, a maioria obteve indicador numérico acima de 70, demonstrando uma tendência a melhor adequação às Diretrizes, considerando valores quanto mais próximos de 100.

\begin{tabular}{|ccc|}
\hline \multicolumn{4}{c|}{$\begin{array}{c}\text { TABELA } \\
\text { Valores do indicador numérico do Perfil } \\
\text { de Formação Profissional (PFP) }\end{array}$} \\
\hline PFP & Frequência & Porcentagem \\
\hline $60-70$ & 9 & 17,65 \\
\hline $71-80$ & 24 & 47,05 \\
\hline $81-90$ & 11 & 21,57 \\
\hline $91-100$ & 7 & 13,73 \\
\hline Total & 51 & 100,00 \\
\hline
\end{tabular}

\begin{tabular}{|ccc}
\multicolumn{3}{c|}{ TABela 5} \\
Valores do indicador numérico do Perfil \\
de Prática Profissional (PPP) \\
\hline PPP & Frequência & Porcentagem \\
\hline $50-60$ & 7 & 13,73 \\
\hline $61-70$ & 12 & 23,53 \\
\hline $71-80$ & 23 & 45,10 \\
\hline $81-90$ & 6 & 11,76 \\
\hline $91-100$ & 3 & 5,88 \\
\hline Total & 51 & 100,00 \\
\hline
\end{tabular}

Os Gráficos 9 e 10 mostram esta tendência de conformidade do perfil do egresso de Medicina do Cesupa com as DCN e a relação destes indicadores com o gênero dos egressos, não havendo diferença estatística entre os perfis de formação e prática profissionais entre homens e mulheres. 
GrÁfico 9

Conformidade do perfil dos egressos de Medicina

com o perfil do egresso preconizado pelas Diretrizes

Curriculares Nacionais segundo o indicador

numérico Perfil de Formação Profissional (PFP)

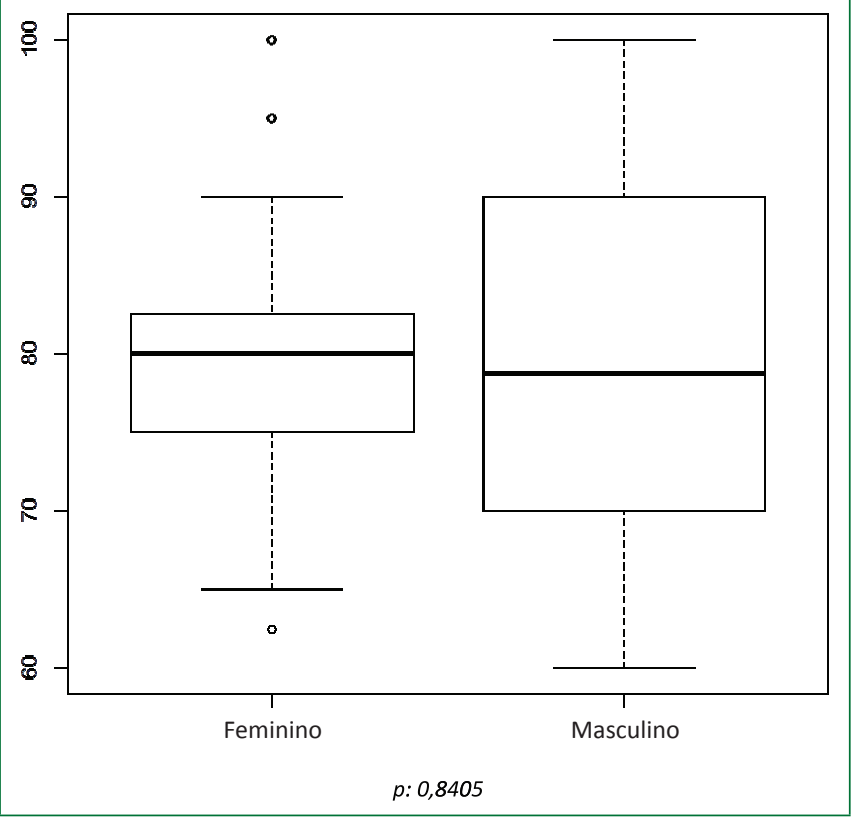

GrÁfico 10

Conformidade do perfil dos egressos de Medicina

com o perfil do egresso preconizado pelas Diretrizes

Curriculares Nacionais segundo o indicador

numérico Perfil de Prática Profissional (PPP)

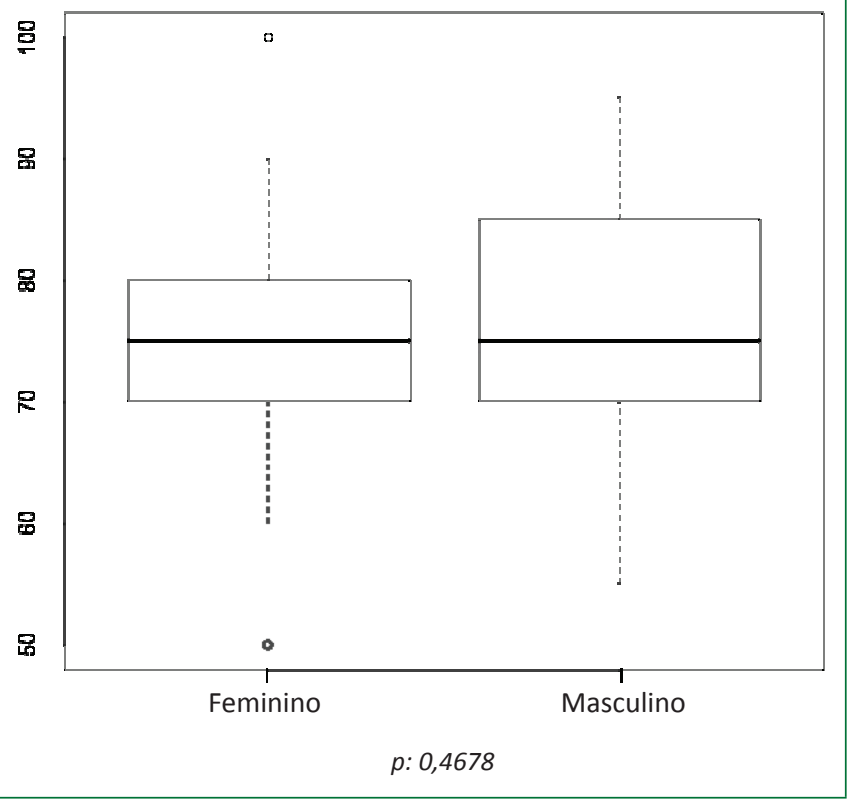

\section{DISCUSSÃO}

O percentual de respostas aos questionários enviados foi considerado satisfatório quando comparado à literatura, cujo índice alcançado em estudos com semelhante desafio metodológico se situa em torno de $20 \%$ a $35 \%$. No presente estudo, foi de $42,85 \%$, semelhante ao obtido por Torres et al..$^{26}(44,9 \%)$ e superior ao obtido por Sousa et al. ${ }^{27}(25,1 \%)$; Sakai e Cordoni ${ }^{19}$ (29,7\%); Caovilla et al..$^{20}$ (32,10\%); Castellanos et al..$^{21}(23,4 \%)$; Magalhães et al..$^{28}$ (22,8\%); Purim et al. ${ }^{23}$ (33,5\%). Uma das limitações deste estudo foi o pequeno número de egressos, o que está relacionado à dificuldade em contatá-los.

Em relação ao gênero, entre os egressos respondentes, foram encontradas mais mulheres, diferentemente dos estudos de Sakai e Cordoni ${ }^{19}$, Magalhães et al. ${ }^{28}$ e Oliveira et al. ${ }^{11}$, nos quais a população de egressos predominante foi de homens - 77,6\%, 74,2\% e 61\%, respectivamente. Porém, a literatura demonstra um aumento da participação da mulher na medicina ao longo das décadas, fenômeno global conhecido como feminização da profissão médica, conforme observado por Gonçalves e Marcondes ${ }^{29}$; Sousa et al. ${ }^{78}$; Sakai e Cordoni ${ }^{19}$; e Dantas ${ }^{18}$.

Dados nacionais de Scheffer et al. ${ }^{30}$ revelaram que o perfil populacional dos médicos inscritos nos Conselhos Regionais de Medicina passou por uma transformação histórica em 2009. Pela primeira vez, houve mais mulheres que homens, e a tendência é que a diferença se amplie em favor das mulheres, pois sua condição feminina há décadas já ultrapassou a esfera doméstica e reprodutiva.

A média de idade dos egressos do Cesupa foi de 28,19 \pm 1,7 ano, o que confirma a característica "jovem" da profissão. Dados semelhantes aos achados de Sousa et al. ${ }^{27}$, Sakai e Cordoni ${ }^{19}$, Caovilla et al. ${ }^{20}$, Magalhães et al..$^{28}$ e Oliveira et al..$^{11}$ demonstram rejuvenescimento dos egressos dos cursos de Medicina. Esse fato pode ser explicado pelo ingresso do estudante ainda muito jovem nas faculdades. Segundo observado por Dantas $^{18}$, em média, os alunos de Medicina se formam com 25,20 anos.

A prevalência de solteiros - 78,43\% - equivale aos dados obtidos por Caovilla et al. ${ }^{20}$, que pesquisaram o perfil do egresso de Medicina da Universidade Luterana do Brasil e encontraram 78,3\% de solteiros. E, ainda, aos dados de Magalhães et al. ${ }^{28}$, que estudaram egressos da Faculdade de Medicina de Juiz de Fora, com achado de 87,1\% de solteiros. Purim et al. ${ }^{23}$ também encontraram maior prevalência de solteiros - 63,5\% - entre os recém-formados no Sul do País. Isto pode ser explicado pelo fato de a Medicina ser um curso de longa duração e integral, que exige dedicação exclusiva e em alguns momentos abdicação de vida social, o que pode gerar atraso na vida conjugal. 
Quanto à renda mensal, a faixa salarial da maioria dos egressos do Cesupa foi semelhante aos resultados do estudo de Sakai e Cordoni ${ }^{19}$, no qual $63 \%$ dos egressos da Universidade Estadual de Londrina têm renda acima de R\$4.001,00. E, ainda, semelhante aos achados de Castellanos et al. ${ }^{21}$, em que $52 \%$ dos egressos da Faculdade de Medicina do ABC ganham entre $\mathrm{R} \$ 4.000,00$ e $\mathrm{R} \$ 10.000,00$.

Porto et al. ${ }^{22}$, analisando egressos do curso de Medicina da Universidade de Fortaleza, detectaram que a maioria tem renda mensal de 12 salários mínimos. Estes dados são semelhantes aos números nacionais de Scheffer et al. ${ }^{8}$, que demonstram que a remuneração do médico brasileiro é de até $\mathrm{R} \$ 8.000,00$, considerando a idade abaixo de 35 anos, correspondente, portanto, à população jovem deste estudo.

A maioria dos egressos mostrou-se satisfeita com o curso de Medicina. Este dado pode ser considerado um viés se considerarmos os ex-alunos respondentes como aqueles que apresentam alguma identificação positiva com o curso e a IES, provavelmente devido à contribuição destes para a sua formação profissional. Estudos futuros com uma amostra mais abrangente poderão complementar esta análise e proporcionar um olhar mais amplo sobre os dados aqui apresentados.

O curso contribuiu totalmente ou em grande parte para a formação na atenção básica, formação humanista, generalista, crítico-reflexiva e ética. Isto pode ser explicado pela matriz curricular do curso do Cesupa, na qual o estudante já inicia o primeiro semestre com o módulo de interação em saúde na comunidade, continuando até o oitavo semestre. Com isso, ele vivencia a realidade local e está inserido no contexto social desde o início dos seus estudos, o que, segundo a proposta das DCN, proporciona ao aluno o confronto com problemas reais e a discussão de assuntos fundamentais a sua formação.

O módulo de interação em saúde na comunidade proporciona aos estudantes conhecimentos, habilidades e atitudes necessários à prática profissional em atenção primária à saúde e busca sensibilizar o futuro profissional quanto à importância do trabalho nas Unidades Básicas de Saúde e prepará-lo para ser participante ativo de programas de base comunitária.

Este dado é corroborado por Ricardo et al. ${ }^{31}$, que, analisando estudantes de Medicina na Estratégia Saúde da Família em séries iniciais, afirmam que a visita domiciliar em séries iniciais exige que o estudante desenvolva a habilidade de comunicação, respeito pelas diferenças e efetiva responsabilização para que seja aceito pelas famílias e, assim, possa desenvolver o seu papel. Além disso, fortalece a formação de profissionais para atuar na atenção básica, pois se caracteriza como um importante cenário de ensino e aprendizagem, o que também é reforçado pelas DCN.
Gonçalves e Pereira ${ }^{32}$, ao estudarem as contribuições da educação geral para a formação de médicos e pedagogos egressos de uma universidade pública, encontraram que cerca de $70 \%$ deles avaliam que a atuação como profissional cidadão está relacionada à formação universitária, sendo que a formação ética e humana ao longo do curso e a vivência no SUS foram as principais características do curso que possibilitaram esta atuação.

Sobre o conhecimento dos ex-alunos a respeito do projeto político-pedagógico da IES durante a graduação, a maioria referiu ter conhecido seu conteúdo totalmente ou em sua maior parte, porém uma parcela de ex-alunos não conheceu o projeto. Por outro lado, em relação às DCN, apenas $29,41 \%$ referiram ter conhecido seu conteúdo totalmente ou em sua maior parte, aumentando o número de ex-alunos que não conheceram o conteúdo das Diretrizes.

Estes achados foram diferentes dos de Filisbino e Moraes ${ }^{4}$, cujo estudo com discentes do internato da Faculdade de Medicina da Universidade Federal de Goiás encontrou maioria com conhecimento superficial tanto das DCN quanto do projeto pedagógico.

No entanto, esta falta de conhecimento acerca do conteúdo das DCN é indireta, uma vez que o projeto pedagógico do curso está norteado pelas Diretrizes, e os egressos reconheceram os cenários de prática oferecidos pelo curso como favoráveis à formação profissional preconizada pelas DCN.

Talvez seja necessário criar momentos na instituição para a apresentação formal do conteúdo das DCN paralelamente ao projeto político-pedagógico, para que os alunos identifiquem os aspectos estruturais que compõem a sua formação pela IES, em um contexto nacional.

Verificou-se que a maioria dos egressos (70,59\%) cursou ou está cursando algum programa de residência médica, de forma semelhante aos achados de Caovilla et al. ${ }^{20}(72,5 \%)$ e Sakai e Cordoni ${ }^{19}(73,6 \%)$, e superior aos resultados de Magalhães et al. ${ }^{28}(35,5 \%)$ e Oliveira et al. ${ }^{11}(64 \%)$. Quando a pesquisa se dá entre egressos mais antigos, este número sobe para mais de $90 \%$, conforme observado por Gonçalves e Marcondes ${ }^{29}$, Dantas $^{18}$, Castellanos et al. ${ }^{21}$ e Torres et al. ${ }^{26}$.

Sabe-se que o ingresso de formandos nos programas de residência médica é bastante concorrido, pois o número de vagas é limitado. Pode-se inferir que a aprovação de ex-alunos em programas de residência médica seja um indicador indireto da qualidade da graduação oferecida.

Por outro lado, os egressos do estudo de Caovilla et al. ${ }^{20}$ consideraram a residência médica necessária para exercer a profissão médica com segurança. Além disto, a busca por formação complementar demonstra a intenção de aperfeiçoamento em determinada área da Medicina, e a residência médi- 
ca é reconhecida no Brasil como a melhor modalidade para a formação de especialistas. Sendo assim, onde estão os médicos generalistas esperados pelas DCN?

Dos egressos respondentes, 66\% afirmaram atuar como médicos generalistas, dado superior ao de Magalhães et al. ${ }^{28}$ (51,6\%). Porém, para isto, há de se considerar o fato de muitos egressos estarem cursando residência e, portanto, ainda não estarem aptos a atuar como especialistas.

Quanto às especialidades mais procuradas, também houve concordância com Caovilla et al. ${ }^{20}$ e Castellanos et al. ${ }^{21}$, provavelmente devido ao fato de que Clínica Médica e Cirurgia Geral são especialidades consideradas pré-requisitos básicos para acesso por residência médica a outras especialidades.

Portanto, o que se observa é ainda o movimento dos egressos para a atuação como especialistas. Aqueles que se mantêm como generalistas talvez o façam devido à não aprovação nos concursos de residência médica ou à necessidade imediata de remuneração salarial, uma vez que o curso é longo, e a IES é particular.

Em relação ao tipo de serviço de atuação, Caovilla et al. ${ }^{20}$ identificaram que $57,97 \%$ dos egressos citaram o setor público como atuação principal, e apenas $34,78 \%$ o setor privado. Oliveira et al. ${ }^{11}$ encontraram $61,4 \%$ atuantes no setor público, enquanto Sakai e Cordoni ${ }^{19}$ acharam 56,6\%. Dantas ${ }^{18}$ também observou maioria de egressos atuando no setor público, apesar do aumento importante de atuação no serviço privado ao longo do século XX, no Pará.

No presente estudo, a quase totalidade dos egressos atua no setor público $(94,12 \%)$, seja de modo isolado ou concomitante ao setor privado, demonstrando quem realmente absorve o jovem egresso médico no mercado de trabalho. Estes percentuais são superiores aos encontrados por Porto et al. ${ }^{22}$, que demonstraram que o Programa Saúde da Família absorve 66\% dos recém-formados na cidade de Fortaleza. Os autores concordam com a afirmação de que o SUS tem papel fundamental na aquisição da mão de obra médica pelo aumento na oferta de empregos.

De fato, além de absorver os egressos no mercado de trabalho, o SUS também tem um papel na formação médica, já que é proposto pelas DCN como cenário de prática desde as séries iniciais do curso, preparando o aluno para sua futura atuação. Considerando também que a formação complementar com residência médica se dá, na quase totalidade dos casos, nos serviços do SUS e que a maioria dos egressos deste estudo busca essa modalidade, já era esperado esse perfil de atuação no setor público.

A grande maioria dos egressos de Medicina do Cesupa $(86,27 \%)$ atua nas capitais, particularmente na Região Norte $(68,62 \%)$. Achado semelhante foi encontrado por Caovilla et al. ${ }^{20}$ ao estudarem egressos no Rio Grande do Sul, onde $84,10 \%$ atuam na capital, Porto Alegre. Purim et al..$^{23}$ também observaram maior percentual de permanência dos egressos no Paraná, sede do curso de Medicina.

Isto demonstra pouca mobilidade do egresso para o interior logo nos primeiros anos de formado, o que pode ser explicado pela aprovação em programas de residência médica, oferecidos em sua maioria nas capitais. Outra explicação para esta permanência na região em que ocorreu a graduação vem do estudo de Oliveira et al. ${ }^{11}$, que analisaram egressos da Amazônia Ocidental. Esse estudo demonstrou que a maioria reside e trabalha nas capitais do Brasil (79\%), sendo que aproximadamente $58 \%$ ficaram no Acre, local da graduação. Eles apontaram os laços familiares (26\%) como causas principais de permanência e melhores propostas de trabalho $(29,7 \%)$ como causas principais de mudança.

Para Sousa et al..$^{27}$ e Porto et al..$^{22}$, os achados foram diferentes. A maioria dos egressos de São José do Rio Preto e Fortaleza, respectivamente, atua no interior. Os achados do atual estudo, portanto, indicam a necessidade de mais médicos no interior e confirmam a má distribuição desses profissionais nas regiões do País descritas por Scheffer et al. ${ }^{8}$.

Sobre sentir-se seguro para o mercado de trabalho, cerca da metade dos egressos do presente estudo se sente razoavelmente preparada para atuar. Na pesquisa de Magalhães et $a l^{28}, 61,3 \%$ dos egressos se sentiam seguros para exercer a profissão sem supervisão. Caovilla et al. ${ }^{20}$ identificaram que, entre os egressos de Medicina da Universidade Luterana do Brasil, apenas $23,19 \%$ se sentiam seguros para atuar sem supervisão e 33,33\% sentiam-se inseguros.

No estudo de Sakai e Cordoni ${ }^{19}$, os médicos declararam que, ao exercerem a prática, não estavam preparados para a realidade. Já no estudo de Oliveira et al. ${ }^{11}$, 66,7\% referiram estar preparados parcialmente para o exercício profissional. Este sentimento de insegurança ou preparo parcial em relação ao mercado de trabalho pode justificar a procura por formação complementar em residências e especializações.

Embora a maioria dos egressos tenha se mostrado satisfeita com o curso de Medicina e referido que ele contribuiu totalmente ou em grande parte para sua formação na atenção básica, formação humanista, generalista, crítico-reflexiva e ética, sabe-se que o início da prática profissional é cercado por muitas expectativas, sendo natural certa insegurança. Seria necessária outra abordagem para identificar os aspectos relacionados à sensação de estar razoavelmente preparado para atuar, referida por estes egressos.

Quanto à existência ou não de conformidade do perfil dos egressos do Cesupa com aquele preconizado pelas Diretrizes Curriculares Nacionais, os indicadores numéricos Perfil 
de Formação Profissional (PFP) e Perfil de Prática Profissional (PPP) demonstraram tendência de conformidade com as DCN, uma vez que a maioria obteve valor mais próximo do máximo (100), o que caracteriza melhor adequação. Não houve diferença estatística entre gêneros.

Essa adequação era esperada por se tratar de um curso com metodologia de ensino inovadora, cujo modelo pedagógico está voltado à formação de médicos com o perfil preconizado pelas DCN.

É importante ressaltar que este é o primeiro estudo sobre os egressos do curso de Medicina desta instituição. O conhecimento acerca da formação e atuação destes profissionais tem extrema importância para a elaboração de políticas institucionais, particularmente no que se refere ao Programa de Acompanhamento de Egressos.

Com base nestes resultados, foi elaborada a Regresso, revista do egresso de Medicina, que terá periodicidade semestral e tiragem de 500 exemplares. Seu principal papel será manter o vínculo do egresso com a instituição e atuais alunos, favorecendo a troca de informações entre eles e colaborando com o aprimoramento do curso. Após o lançamento do primeiro exemplar, os seguintes ficarão sob responsabilidade da própria instituição por meio de sua Assessoria de Comunicação.

Não foi encontrado, na literatura, material semelhante com este fim. E, ainda, esta estratégia de vínculo com os egressos pode ser reproduzida por qualquer IES e para qualquer curso, pois representa um importante produto de gerenciamento de egressos, constituindo uma medida institucional para incentivar a participação de ex-alunos na vida da instituição, seguindo o que propõe o Sinaes.

Para um futuro próximo, sugerem-se mais estudos sobre egressos desta e de outras instituições com o intuito de contínua melhoria do processo ensino-aprendizagem dos cursos médicos, uma vez que o conhecimento sobre o perfil do médico que está sendo formado é fundamental para aprimorar a prática médica e subsidiar as discussões sobre reforma curricular nas escolas médicas.

Como propostas de intervenção, indo ao encontro do que é preconizado pelas DCN e esperado pela sociedade, há de se fomentar a maior mobilidade de egressos para as cidades de interior e apresentar formalmente o conteúdo das Diretrizes aos profissionais em formação.

\section{CONCLUSÃO}

O perfil sociodemográfico dos egressos de Medicina do Cesupa é caracterizado, em sua maioria, por mulheres, com menos de 30 anos de idade, solteiras e com renda mensal entre seis e dez salários mínimos.
O perfil de formação mostrou egressos satisfeitos com o curso, que contribuiu totalmente ou em grande parte para a formação na atenção básica e formação humanista, generalista, crítico-reflexiva e ética. Durante a graduação, a maioria teve conhecimento total ou em sua maior parte do projeto pedagógico do curso, porém uma parcela de egressos não conheceu o conteúdo das DCN.

Ainda sobre a formação profissional, a maioria dos egressos cursou ou está cursando um programa de residência médica, sendo a Clínica Médica a área mais escolhida, seguida de Cirurgia Geral e Pediatria.

O perfil de atuação profissional revelou médicos atuantes no SUS, como generalistas, alocados nas capitais, particularmente na Região Norte, sentindo-se razoavelmente preparados para o mercado de trabalho, porém referindo ser competentes.

Foi observada tendência de conformidade do perfil desses egressos com aquele preconizado pelas Diretrizes Curriculares Nacionais, e a contribuição para o Programa de Acompanhamento de Egressos da IES se deu por meio da elaboração da Revista do Egresso - Regresso, medida adotada para favorecer um vínculo maior entre o ex-aluno e seu órgão formador.

\section{REFERÊNCIAS}

1. FRANCO CAGS; CUBAS MR; FRANCO RS. Currículo de medicina e as competências propostas pelas Diretrizes Curriculares. RevBrasEducMed; v.38, n. 2, p.221-230, 2014.

2. PAGLIOSA FL ; DA ROS MA. O relatório Flexner : para o bem e para o mal. Rev Bras EducMed;v. 32, n. 4, p. 492499, 2008.

3. RIBEIRO RC; FONSECA-GUEDES CHF; NUNES MPT. Médicos recém-formados: sólida formação geral ou sólida formação especializada?.RevBrasEducMed; v .33, n.4, p.571-585;2009.

4. FILISBINO MA; MORAES VA. A graduação médica e a prática profissional na perspectiva dos discentes. RevBrasEducMed; v.37, n.4, p. 510-548, 2013.

5. OLIVEIRA NA; ALVES LA. Ensino médico, SUS e início da profissão: como se sente quem está se formando? Rev Bras EducMed; v. 35, n. 1, p. 26-36, 2011.

6. ROSSONI E; LAMPERT JB. Formação de profissionais para o sistema único de saúde e as diretrizes curriculares. Boletim da Saúde; v.18, n.1, 2004.

7. MICHELAN e col. Gestão de egressos em IES: possibilidades e potencialidades, 2009.

8. SCHEFFER, M. et al.Demografia Médica no Brasil. Cenários e indicadores de distribuição. 2013. v. 2. Disponível em: <http://portal.cfm.org.br/images/stories/pdf/de- 
mografiamedicanobrasil_vol2.pdf $>$. Acesso em: 12 fevereiro 2015.

9. NASSIF, A. C. N. As Escolas Médicas do Brasil. São Paulo, 2013. Disponível em: <http://www.escolasmedicas.com. br>. Acesso em 30.12.2016.

10. LOPES, LRS. Demografia médica: provimento e fixação de médicos em áreas de maior vulnerabilidade. Rio de Janeiro. Monografia apresentada ao Departamento de Estudos da Escola Superior de Guerra; 2013.

11. OLIVEIRA JGS ; PAULA GO ; ARAUJO TS. A formação, o trabalho e fixação de egressosmédicos na Amazônia Ocidental. Rev IntHumanid Med; v.4, n.2, p. 101-114, 2015.

12. CONSELHO FEDERAL DE MEDICINA. Radiografia das Escolas Médicas do Brasil. São Paulo, 2015. Disponível em: <http://webpainel.cfm.org.br/>. Último acesso em 25.06.2016.

13. STELLA, RCR, and PUCCINI, RF. A formação profissional no contexto das Diretrizes Curriculares nacionais para o curso de medicina. In PUCCINI, RF; SAMPAIO, LO; BATISTA, NA. A formação médica na Unifesp: excelência e compromisso social [online]. São Paulo: Editora Unifesp, 2008. p. 53-69. ISBN 978-85-61673-66-6.

14. MINISTÉRIO DA EDUCAÇÃO. CONSELHO NACIONAL DE EDUCAÇÃO. Câmara de Educação Superior. Resolução n.4, CNE/CES de 07/11/2001. Diretrizes curriculares nacionais do curso de graduação em medicina. Diário Oficial da União. Brasília 09 nov 2001, Seção 1, p.38.

15. MINISTÉRIO DA EDUCAÇÃO. CONSELHO NACIONAL DE EDUCAÇÃO. Câmara de Educação Superior. Resolução n.3, CNE/CES de 20/06/2014. Diretrizes curriculares nacionais do curso de graduação em medicina. Diário Oficial da União. Brasília 23 jun 2014, Seção 1, p.811.

16. SILVA, EVM et al. Construção de currículos e a formação dos trabalhadores de saúde. Publicação do Núcleo de Gestão do Trabalho e Educação na Saúde do CONASEMS. Disponível em: www.cosemsms.org.br/publicacoes/formacao_ profissionais_2008.pdf

17. BERBEL, NAN. As metodologias ativas e a promoção da autonomia dos estudantes. Semina: Ciências Sociais e Humanas, Londrina, v. 32, n. 1, p. 25-40, jan./jun. 2011.

18. DANTAS, AB. Egressos de Medicina no Pará. Dissertação (Mestrado) - Universidade Federal do Pará, Centro de Educação, Mestrado em Educação, Belém, 2006.

19. SAKAI MH, CORDONI JUNIOR L. Os egressos da medicina da universidade Estadual de Londrina: sua formação e prática médica. Rev Espaço para a Saúde, v.6, n.1, p.34-47, 2004.
20. CAOVILLA F; LEITZKE L; MENEZES HS; MARTINEZ PF. Perfil do egresso de Medicina da Universidade Luterana do Brasil (Ulbra). Revista da AMRIGS, 52(2):103-109, abr/ jun. 2008.

21. CASTELLANOS MEP et al. Perfil dos egressos da Faculdade de Medicina do ABC: o que eles pensam sobre atenção primária em saúde? ArqBrasCienSaúde, v.34, n.2, p.71-9, 2009.

22. PORTO MMA; BARBOSA GL; MAIA APF; VERAS VR; ALBUQUERQUE CA. Perfil dos egressos do curso de Medicina da Universidade de Fortaleza. AnCongrBrasMedFam Comunidade. Belém, 2013 Maio; 12:158

23. PURIM KSM; BORGES LMC; POSSEBOM AC. Perfil do médico recém-formado no sul do Brasil e sua inserção profissional. Rev. Col. Bras. Cir. 2016; 43(4): 295-300.

24. NOVAES et al.Actitudes Éticas de los estudiantes y egresados em carrera de medicina commetodologíasactivas. RevBrasEducMed, v. 34, n. 1, p.43-56, 2010.

25. MINISTÉRIO DA EDUCAÇÃO - MEC. Avaliação externa das Instituições de educação superior: diretrizes e instrumentos. 2006. Disponívelem: http://www.inep.gov.br/ download/superior/2005/avaliacao_institucional/avaliacao_institucional_externa_8102005.pdf.

26. TORRES AR; RUIZ T; MULLER SS; LIMA MCP. Inserção, Renda e Satisfação Profissional de Médicos Formados pela Unesp. RevBrasEducMed; v.36, n.1, p. 31-40, 2012.

27. SOUZA GMB, CRUZ EMTN, CORDEIRO JA. Perfil do egresso da Faculdade de Medicina de São José do Rio Preto. Rev Bras EducMed; v.26, n.2, p.105-14, 2002.

28. MAGALHÃES e col. Perfil dos egressos de Medicina de uma Faculdade de Medicina de Juiz de Fora/MG. Rev Ciências em Saúde; v.2, n.2, abr. 2012.

29. GONÇALVES EL; MARCONDES M. Perfil do ex-aluno da Faculdade de Medicina da Universidade de São Paulo. Rev HospClinFac Med Sao Paulo; v.46, n.2, p. 99-107, 1991.

30. SCHEFFER, M. et al. Demografia médica no Brasil 2015. V.3. Disponível em: <http://www.flip3d.com.br/web/ $\mathrm{pub} / \mathrm{cfm} /$ infex10/numero=12\#page/1>. Acesso em: 16 dezembro 2015.

31. RICARDO MPF; MARIN MJS; OTANI MAP; MARIN MS. Estudante de medicina na estratégia saúde da família em séries iniciais: percepção dos egressos. RevEscEnferm USP 2014; 48(Esp2):187-192.

32. GONÇALVES ML; PEREIRA EMA. Contribuições da educação geral na formação de médicos e pedagogos egressos de uma universidade pública. Avaliação, Campinas; Sorocaba, SP, v. 20, n. 2, p. 513-530, jul. 2015. 


\section{COLABORAÇÃO DOS AUTORES}

Cristiane Ribeiro Maués: pesquisadora principal

Bruno Acatauassu Paes Barreto: orientador da pesquisa

Márcia Bitar Portella: orientadora da pesquisa

Haroldo José de Matos: análise estatística dos dados

Julio Cristovão Carvalho dos Santos: diagramação e projeto

gráfico da Revista, produto da pesquisa

\section{CONFLITO DE INTERESSES}

Não há conflito de interesses

\section{ENDEREÇOS PARA CORRESPONDÊNCIA}

Tv. Pirajá, 716 ap 101 B, CEP 66.083-514, Bairro Pedreira, Belém - Pará

\section{APÊNDICE A - QUESTIONÁRIO}

PARTE 1: PERFIL SÓCIODEMOGRÁFICO

1. IDADE: (anos)

2. GÊNERO: ( )feminino ( )masculino

3. EST. CIVIL: ( )casado ( )solteiro ( )união estável ( )divorciado/separado

4. LOCAL DE RESIDÊNCIA (Cidade/Estado):

5. RENDA MENSAL (em salários mínimos):
( ) 01-05
( ) $06-10$
( ) 11-15
( ) $16-20$
( ) acima de 20

PARTE 2: PERFIL DE FORMAÇÃO PROFISSIONAL

1. ANO DE CONCLUSAO DO CURSO: 201

2. DURANTE A GRADUAÇÃO VOCÊ CONHECEU O PROJETO POLÍTICO-PEDAGÓGICO DO CESUPA?
( ) Sim, conheci totalmente
( ) Sim, conheci a maior parte
( ) Conheci razoavelmente
( ) Conheci apenas superficialmente
( ) Não conheci.

3. DURANTE A GRADUAÇÃO VOCÊ CONHECEU AS DIRETRIZES CURRICULARES NACIONAIS PARA O CURSO DE MEDICINA?
( ) Sim, conheci totalmente
( ) Sim, conheci a maior parte
( ) Conheci razoavelmente
( ) Conheci apenas superficialmente

( ) Não conheci.

4. O CURSO FAVORECEU A SUA FORMAÇÃO NA ATENÇÃO BÁSICA?
( ) Sim, totalmente
( ) Sim, em grande parte
( ) Sim razoavelmente
( ) Sim mas apenas superficialmente
( ) Não.

5. O CURSO FAVORECEU A SUA FORMAÇÃO MÉDICA HUMANISTA?
( ) Sim, totalmente
( ) Sim, em grande parte
( ) Sim razoavelmente
( ) Sim mas apenas superficialmente
( ) Não.

6. O CURSO CONTRIBUIU PARA SUA FORMAÇÃO COMO MÉDICO GENERALISTA?
( ) Sim, totalmente
( ) Sim, em grande parte
( ) Sim razoavelmente
( ) Sim mas apenas superficialmente
( ) Não.

7. O CURSO CONTRIBUIU PARA SUA FORMAÇÃO COMO MÉDICO CRÍTICO-REFLEXIVO ?
( ) Sim, totalmente
( ) Sim, em grande parte
( ) Sim razoavelmente
( ) Sim mas apenas superficialmente
( ) Não

8. O CURSO CONTRIBUIU PARA SUA FORMAÇÃO ÉTICA?
( ) Sim, totalmente
( ) Sim, em grande parte
( ) Sim razoavelmente
( ) Sim mas apenas superficialmente
( ) Não.

9. NUMA ESCALA DE 1 A 5, QUAL O SEU GRAU DE SATISFAÇÃO COM O CURSO DE MEDICINA, sendo 1 totalmente insatisfeito e 5 totalmente satisfeito.
( ) 1
( ) 2
( ) 3
( ) 4
( ) 5 
10. CURSOU ou ESTÁ CURSANDO RESIDENCIA MEDICA?
( ) Não
( ) Sim. Qual área?

PARTE 3: PERFIL DE PRÁTICA PROFISSIONAL

1. EM QUAL(IS) TIPO(S) DE ATIVIDADE VOCÊ EXERCE SUA PROFISSÃO?

( ) Somente no serviço público de saúde/SUS

( ) Somente no sistema privado

( ) SUS e sistema privado

( ) não exerço a profissão atualmente

( ) outros tipos:

2. VOCÊ ATUA COMO:

( ) Médico generalista

( ) Médico especialista

3. LOCAL DE TRABALHO (Cidade/estado):

4. VOCÊ SENTE-SE PREPARADO PARA O MERCADO DE TRABALHO?
( ) Sim, estou totalmente preparado
( ) Sim, mas com algumas deficiências
( ) Sinto-me razoavelmente preparado
( ) Sinto-me mal preparado
( ) Sinto-me totalmente despreparado para as atuais demandas

CONSIDERANDO COMPETÊNCIA COMO A CAPACIDADE DE MOBILIZAR CONHECIMENTOS, HABILIDADES E ATITUDES, COM UTILIZAÇÃO DE RECURSOS DISPONÍVEIS PARA SOLUCIONAR DESAFIOS QUE SE APRESENTAM NA PRÁTICA MÉDICA, PRINCIPALMENTE NOS CENÁRIOS DO SUS, COMO VOCÊ AVALIA EM SUA PRÁTICA PROFISSIONAL:

5. SUA COMPETÊNCIA NA ATENÇÃO À SAÚDE (Identificação das necessidades de saúde individual e coletiva, e desenvolvimento de planos terapêuticos)
( ) Muito competente
( ) Competente
( ) Razoavelmente competente
( ) Pouco competente
( ) Nada competente

6. SUA COMPETÊNCIA NA GESTÃO EM SAÚDE (aptidão a desenvolver ações de gerenciamento e administração, liderança democrática e trabalho em equipe)
( ) Muito competente
( ) Competente
( ) Pouco competente
( ) Nada competente
( ) Razoavelmente competente

7. SUA COMPETÊNCIA NA EDUCAÇÃO EM SAÚDE (aptidão a aprender continuamente, socializar o conhecimento e participar da formação de futuros profissionais)
( ) Muito competente
( ) Competente
( ) Razoavelmente competente
( ) Pouco competente
( ) Nada competente

\section{APÊNDICE B -TERMO DE CONSENTIMENTO LIVRE E ESCLARECIDO (TCLE)}

Caro(a) colega, você está sendo convidado(a) a participar como voluntário(a) de uma pesquisa. Meu nome é Cristiane Ribeiro Maués, docente do Curso de Medicina do CESUPA, matriculada no Programa de Mestrado Profissional da Universidade do Estado do Pará. Após receber os esclarecimentos e as informações a seguir, em caso de aceitar fazer parte do estudo, assine ao final deste documento, o qual está em duas vias, uma delas é sua e a outra da pesquisadora. Em caso de recusa, você não será penalizado de forma alguma. Você poderá retirar a qualquer tempo o seu consentimento. Se houver dúvida sobre a pesquisa, poderá entrar em contato com a pesquisadora pelo telefone (91) 982506044. Em caso de dúvida quanto aos seus direitos como participante do estudo, poderá entrar em contato com o Comitê de Ética em Pesquisa do CESUPA pelo telefone: (91) 40092100 ou endereço: Av. Nazaré 630.

\section{INFORMAÇÕES IMPORTANTES SOBRE A PESQUISA}

TEMA: Egressos de um curso de medicina baseado em metodologias ativas de ensino e sua atuação profissional.

A motivação deste estudo é avaliar se os médicos formados com metodologias ativas tem o perfil do egresso preconizado pelas Diretrizes Curriculares Nacionais (DCN). A coleta de dados será feita no ano de 2015, através de um questionário que consta 
de dados sobre o perfil sociodemográfico do egresso, aspectos relacionados à sua formação e prática profissionais. As questões são simples e objetivas. O anonimato é parte integrante desta pesquisa, não havendo espaço para identificação nominal do participante. Necessito imensamente de sua colaboração, sem a qual será impossível o alcance dos objetivos propostos. Os resultados deste estudo serão muito úteis para proporcionar vínculo da Instituição com seus ex-alunos e contribuir para um ensino médico de qualidade e que forme profissionais capazes de atender as demandas de saúde da população. Os riscos, ainda que mínimos, podem ocorrer como, por exemplo, sentir-se constrangido a participar pelo fato de ter sido aluno da instituição e da pesquisadora. Ao participante não será garantido nenhum benefício direto ou gratificação financeira proveniente da referida pesquisa. Antecipadamente agradeço pela sua atenção e colaboração.

\section{CONSENTIMENTO DE PARTICIPAÇÃO COMO SUJEITO DE PESQUISA}

Finalmente, tendo eu compreendido perfeitamente tudo o que me foi informado sobre a minha participação no mencionado estudo e estando consciente dos meus direitos, das minhas responsabilidades, dos riscos e dos benefícios que a minha participação implicam, concordo em dele participar e dou o meu consentimento sem que para isso eu tenha sido forçado ou obrigado.

Local e data:

Endereço da responsável pela pesquisa: Centro Universitário do Pará - CESUPA

Av. Almirante Barroso n 3775. CEP:66013903. Belém-PA. Telefone: (91)32059000

Assinatura do voluntário da pesquisa

Nome e Assinatura da responsável pela pesquisa 